\title{
Efeito da temperatura e do fotoperíodo na germinação in vitro de conídios de Alternaria dauci, agente etiológico da queima das folhas da cenoura
}

\author{
Leandro Luiz Marcuzzo ${ }^{1}{ }^{\circ}$, Jéssica Costa $\operatorname{Santos}^{1}{ }^{1}$
}

\begin{abstract}
${ }^{1}$ Instituto Federal Catarinense - IFC/Campus Rio do Sul, CP 441, 89.163-356, Rio do Sul, SC, Brasil
Autor para correspondência: Leandro Luiz Marcuzzo (leandro.marcuzzo@ifc.edu.br)

Data de chegada: 15/03/2018. Aceito para publicação em: 05/02/2019.
\end{abstract}

$10.1590 / 0100-5405 / 192990$

A queima das folhas da cenoura causada por Alternaria dauci (Kühn) Groves \& Skolko destaca-se como a mais importante doença foliar dessa cultura. Esta doença está amplamente disseminada em regiões produtoras, onde são frequentes os períodos de altas temperaturas e umidade (1). Epidemias são favorecidas por temperaturas entre 15 a $26^{\circ} \mathrm{C}$ e umidade relativa acima de $90 \%$ (4). Os primeiros sintomas da doença geralmente ocorrem nas folhas mais velhas e baixeiras e em torno de 8-10 dias da infecção, as folhas apresentam lesões marrom-esverdeadas. Com o desenvolvimento dos sintomas, os tecidos tornam-se marrom-escuros a pretos, podendo ser circundados por halos amarelos, sendo que essas lesões aparecem com maior frequência nas margens das folhas (6). Sabe-se que a germinação de esporos de fungos é influenciada diretamente pela temperatura e fotoperíodo, no entanto as informações desse patógeno são escassas. O conhecimento da biologia do patógeno é de importância para compreender o desenvolvimento da doença no campo, bem como para tomar medidas de manejo da doença. Diante disto, este trabalho teve como objetivo avaliar em condições in vitro a influência da temperatura e do fotoperíodo na germinação de conídios de $A$. dauci. A pesquisa foi realizada no Laboratório de Microbiologia e Fitopatologia do Instituto Federal Catarinense/ Campus Rio do Sul com isolado identificado de A. dauci obtido de plantas de cenoura com sintoma da doença a campo e isolado de folhas em meio de cultura BDA (Batata-dextrose-agar). O experimento foi em delineamento inteiramente casualizado com cinco repetições. $\mathrm{O}$ isolado foi multiplicado em placas de Petri contendo meio de cultura BDA por sete dias a $25^{\circ} \mathrm{C}$ e 12 horas de fotoperíodo em câmara de germinação do tipo B.O.D. (Demanda biológica de oxigênio). Após esse período as placas foram submetidas a raspagem com lamina de vidro para favorecer a esporulação e incubado por mais 48 horas. Os conídios foram retirados do crescimento através de lavagem com água estéril com um pincel (nº) e espalhou-se com auxílio de alça de Drigalski $100 \mu 1$ de suspensão de conídios contendo a concentração de $1 \times 10^{4}$ conídios/mL junto com $100 \mu 1$ de uma suspensão (agitada por 15 minutos) de $10 \%$ de extrato aquoso de fragmentos $(0,5 \mathrm{~cm})$ de folha de cenoura (para favorecer a germinação dos conídios) em placas de Petri contendo meio Agar-Água 1\%. Em seguida, as placas foram incubadas em B.O.D a temperaturas de 1, 5, 10, 15, 20, 25, 30, 35,40 e $45^{\circ} \mathrm{C}$ e zero horas de fotoperíodo. Em um segundo momento repetiu-se o experimento incubando conídios de $A$. dauci em B.O.D a $22^{\circ} \mathrm{C}$ (temperatura ideal de germinação obtida com o experimento da temperatura) com os fotoperíodos de 0, 6, 12, 18 e 24 horas luz. Ambos os experimentos foi avaliada a percentagem de germinação após 24 horas de incubação. A contagem dos conídios nas placas de Petri foi feita com microscópio óptico a 10 vezes de aumento através da contagem de 100 conídios aleatórios na placa. Foi considerado germinado o que tivesse o tubo germinativo maior ou igual ao comprimento do conídio. Com base nos resultados obtidos, constatou-se a que temperatura exerce grande influência sobre a germinação dos conídios de $A$. dauci. Observa-se que entre as temperaturas de 15 e $30^{\circ} \mathrm{C}$ (Figura 1A) houve uma alta percentagem de germinação variando ente 99 e $100 \%$ respectivamente, onde os maiores percentuais de germinação (100\%) ocorreram no intervalo de 25 a $30^{\circ} \mathrm{C}$, temperaturas essas, dentro da faixa de desenvolvimento da doença $(1,4)$. Park et al. (2) também verificaram maior geminação na faixa de 15 a $25^{\circ} \mathrm{C}$, semelhante ao encontrado esse trabalho, apesar de não terem avaliado a $30^{\circ} \mathrm{C}$. A germinação dos conídios de $A$. dauci é bruscamente reduzida em temperaturas extremas, pois a $40^{\circ} \mathrm{C}$ a percentagem de germinação foi de apenas $1,2 \%$, sendo $98,8 \%$ inferior a germinação a $35^{\circ} \mathrm{C}$ e na temperatura de $1{ }^{\circ} \mathrm{C}$ não foi observado germinação. Verificou-se que a $5^{\circ} \mathrm{C}$ teve $31,8 \%$ de germinação com $198 \%$ inferior a germinação obtida a $10^{\circ} \mathrm{C}$. Por meio
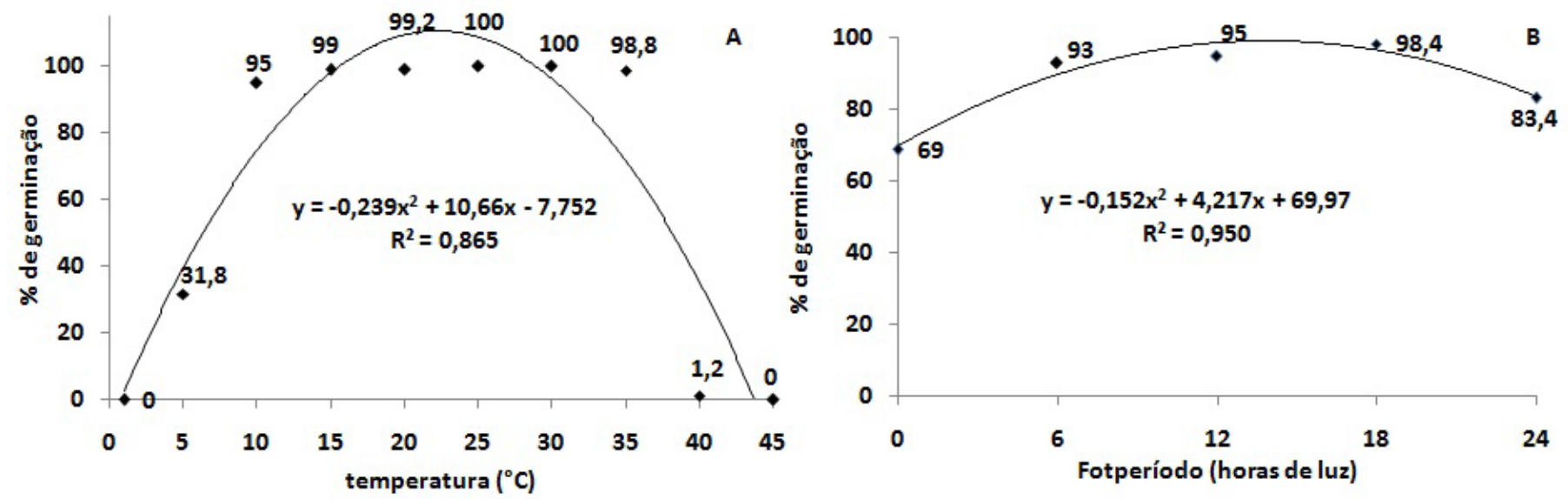

Figura 1. Curva da germinação de conídios de A. dauci sob diferentes temperaturas (A) e diferentes fotoperíodos (B). IFC/Campus Rio do Sul, 2018. 
da equação gerada pela curva $y=-0,239 \mathrm{x}^{2}+10,66 \mathrm{x}-7,752\left(\mathrm{R}^{2}=0,865\right)$ (Figura 1A) a temperatura ótima para a germinação de conídios de $\mathrm{A}$. dauci foi de $22^{\circ} \mathrm{C}$, resultado igual ao utilizado por Stramdberg (5) para avaliar a germinação e infecção de $A$.dauci em inflorescência de cenoura. Em relação a germinação de conídios em diferentes fotoperíodos observou-se uma resposta polinomial (Figura 1B), que através da equação $y=-0,152 \mathrm{x}^{2}+4,217 \mathrm{x}+69,97\left(\mathrm{R}^{2}=0,950\right)$, verificou-se que o fotoperíodo mais favorável ao desenvolvimento é de 14 horas de luz, com 99,2\% dos conídios germinados quando comparado com zero horas de luz que obteve apenas $69 \%$, porém pouco expressiva a diferença do fotoperíodo ao se comparar com a temperatura. Pulz \& Massola Junior (3) avaliando diferentes regimes de luminosidade sobre a esporulação de $A$. dauci também constataram o ideal de 12 horas luz/escuro, próximo ao ocorrido nesse trabalho para a germinação. Mediante a isso é possível que $A$. dauci tem sua germinação favorecida por maiores períodos de luz, assim em dias mais longos e com mais luminosidade como o que acontece durante o cultivo na primavera/ verão favorecem a germinação dos conídios e ocorrência da doença desde que as condições de temperatura sejam atendidas. Conclui-se que a germinação dos conídios de $A$. dauci sofre influência da temperatura e do fotoperíodo, onde as maiores percentagens de germinação são obtidas em temperaturas de 10 a $35^{\circ} \mathrm{C}$, sendo a temperatura ótima $22^{\circ} \mathrm{C}$, e o fotoperíodo em torno de 12 horas luz. As informações obtidas em relação à temperatura e o fotoperíodo na germinação dos conídios de $A$. dauci permitem um maior conhecimento da biologia do agente causal da queima das folhas da cenoura, auxiliando assim no entendimento da epidemiologia da doença a campo. Os resultados obtidos servirão de suporte na elaboração de um sistema de previsão da doença.

\section{REFERENCIAS}

1. Henz, G.P.; Lopes, C.A.; Reis, A. Manejo de Doenças. In: Nick, C.; Borém, A. (Ed.). Cenoura: do plantio a colheita. UFV: Viçosa, p.98-123, 2016.

2. Park, K.H.; Yun, H.J.; Ryu, K.Y.; Yun, J.C.; kim, S.R.; Kim, W.I.; Kim, D.H.; Kwon, Y.C.; Cha, B. Influence of environmental factors on conidial germination of Alternaria dauci. Reserch in plant disease, Seoul, v.17, n.3, p.381-385, 2011.

3. Pulz, P.; Massola Jr., N.S. Efeito de meios de cultura e fatores físicos no crescimento e esporulação de Alternaria dauci e A. solani. Summa Phytopathologica, Botucatu, v.35, n.2, p.121-126, 2009.

4. Reis, A. Queima das folhas: uma doença complexa. Brasília: $\mathrm{CNPH}$, 2010,8p. Circular técnica 91

5. Strandberg, J.0. Infection and colonization of inflorescences and mericarps of carrot by Alternaria dauci. Plant Disease, St. Paul, v. 67, n.12, p.13511353,1983

6. Töfoli, J.G.; Domingues, R.J. Sintoma, etiologia e manejo da queima das folhas (Alternaria dauci; Cercospora carotae) na cultura da cenoura. Biológico, São Paulo, v.72, n.1, p.47-50, 2010. 